SOCIAL RESEARCH REPORTS

ISSN: 2066-6861 (print), ISSN: 2067-5941 (electronic)

\title{
DEPRESSION AMONG THE ISRAELI ADULT POPULATION: SOCIO-DEMOGRAPHIC CHARACTERISTICS AND CULTURAL ASPECTS
}

Dolev KAROLINSKY

Social Research Reports, 2019, Vol. 11, Issue 1, pp. 35-53

The online version of this article can be found at:

www. researchreports.ro

\section{https://doi.org/10.33788/srr11.1.3}

Published by:

Expert Projects Publishing House

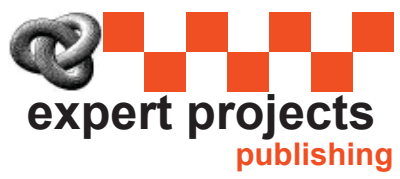

Covered by Index Copernicus International www.indexcopernicus.com

Directory of Open Access Journals

www.doaj.org

On behalf of:

Center for Program and Social Development

Aditional services and information about Social Research Reports can be found at: www.researchreports.ro 


\title{
DEPRESSION AMONG THE ISRAELI ADULT POPULATION: SOCIO-DEMOGRAPHIC CHARACTERISTICS AND CULTURAL ASPECTS
}

\author{
Dolev KAROLINSKY $Y^{1,2}$
}

\begin{abstract}
Depression constitutes one of the main causes for disability around the world. Although the association between socio-demographic and depression were examined in previous studies worldwide, these findings remained inconclusive. Moreover, population-based studies aimed to identify risk factors for depression are scarce in Israel. The main purpose of the current study is estimating the prevalence of depression among Israeli adults and identifying socio-demographic predictors for depression among Jews and Arabs, including the independent role of population group. Data were used from the third Israeli national health interview survey $(\mathrm{N}=3,765)$. Depression was identified by shortened five-item version of the Mental Health Index (MHI-5). Two-tailed $\chi 2$ analyses examined associations between socio-demographic and depression among the Jewish and Arab population groups. Logistic regression models were used for multivariable analyses in each population group. The prevalence of depression in the sample was $13.8 \%, 9.3 \%$ in Jews and $23.9 \%$ in Arabs. Population group was found to be independent risk factor for depression $(\mathrm{OR}=2.8, \mathrm{p}<0.01)$. In the Jewish population, women $(\mathrm{OR}=1.6, \mathrm{p}<0.01)$, interviewees who live alone $(\mathrm{OR}=1.8, \mathrm{p}<0.01)$ and those who have low education level $(\mathrm{OR}=2.0, \mathrm{p}<0.01)$ were more likely to be depressed. In the Arab population, women $(\mathrm{OR}=2.0, \mathrm{p}<0.01)$, interviewees aged 21-64 $(\mathrm{OR}=3.7, \mathrm{p}<0.01)$ and those who live in the north $(\mathrm{OR}=1.9, \mathrm{p}<0.05)$ or in the south $(\mathrm{OR}=2.0, \mathrm{p}<0.05)$ areas were more likely to be depressed. Differences in depression rates between Jews and Arabs may be related to cultural issues affecting coping patterns with depression. The current study reinforces the need in tailoring a unique intervention plan for each population group, focusing on the sub-groups at higher risk for depression. These programs should put an emphasis on socio-demographic and cultural aspects, in order to plan interventions that result in enhancing the compliance with depression treatment and in reducing the extent of this disorder in Israel.
\end{abstract}

Keywords: depression, Jewish population, Arab population, socio-demographic characteristics, culture, social environments, social cohesion.

\footnotetext{
${ }^{1}$ The Max Stern Yezreel Valley College, Yezreel Valley, ISRAEL. E-mail: dolevka@gmail.com

${ }^{2}$ West University Timisoara, Timisoara. ROMANIA.
} 


\section{Introduction}

Depression constitutes one of the main causes for disability around the world. According to the World Health Organization (WHO), 350 million individuals worldwide suffer from depression (WHO, 2016).Depression is characterized by depressed mood throughout the day, loss of pleasure and interest and decreased vitality continuing over time. The severity of symptoms might be expressed by a significant decline in the level of functioning of the individual in different domains of life, such as employment and studies (Elizur et al., 2010). It is evident that the social environments in modern-industrialized countries become more and more socially isolating, competitive and threatening. This trend may cause to lower levels of social cohesion in developed countries that in turn play a role in the raising rates of depression (Hidaka, 2012).

According to the Diagnostic and Statistical Manual of Mental Disorders $5^{\text {th }}$ Edition (DSM-V) the main type of depressive disorders is major depressive disorder. Major depressive is diagnosed if at least five of the following symptoms are presented most of the day for at least two weeks: 1) depressed mood; 2) lost of interest or pleasure; 3) significant change in weight or appetite; 4) insomnia or hypersomnia; 5) psychomotor agitation or retardation; 6) fatigue or loss of energy; 7) worthlessness feelings or excessive guilt; 8) diminished ability to think or concentrate or indecisiveness; 9) recurrent thoughts of death or suicide. In addition, at least one the two first symptoms mentioned above should be presented for the diagnosis of major depressive disorder. The presented symptoms must result in clinically significant distress or impairment in social, occupational or other important domain of functioning. The diagnosis of major depressive disorder will be ruled out in case these symptoms are derived from direct physiological factors such as substance use (for instance, drugs use) or a certain medical condition (for example, sub-activity of the thyroid gland) (American Psychiatric Association [APA], 2013). However, similarly to major depressive disorder, sub-threshold symptoms of depression were also related to increased risk for morbidity, disability, decreased quality of life and mortality (Geulayov, Lipsitz, Sabar \& Gross, 2007).

The WHO has conducted mental health surveys since 2001 in several countries, including Israel (WHO, 2005). One of the findings of these surveys was that the point prevalence rate of major depressive disorder (in the last 12 months) is approximately $6 \%$ (Kessler et al., 2010; Kessler \& Bromet, 2013). During the years 2003-2004 the WHO survey was conducted in Israel and similar rate of major depressive disorder was reported (5.9\%) (Levinson et al., 2007). In other studies focused on depressive symptoms (including sub-threshold depression), the rates of depression ranged from $19.7 \%$ to $23.0 \%$ (Iancu et al., 2003). Similar rates were reported in Israel in the past years: $21.5 \%$ in 2000 and 17.8\% in 2006 (Kaplan et al., 2010; Iancu et al., 2003).

Former studies have already found associations between socio-demographic characteristics and depression (Kaplan et al., 2010; Iancu et al., 2003). Studies show that the risk for depression is higher among minority population groups in western countries. For instance, it was found that the risks for depression in the USA were 1.2 and 1.4 higher among African American and Hispanic, respectively, than White adults (Dunlop, Song, Lyons, Manheim \& Chang, 2003). Similar 
trends were reported in one Israeli study a decade ago; Higher rates of depression were found among the Arabs compared with the Jewish adults $(24.9 \%$ and $10.6 \%$, respectively) (Kaplan et al., 2010).

Women were found to have higher risk for depression than men (Kessler \& Bromet, 2013; Piccinelli \& Wilkinson, 2000). In several large-scale studies, depression among women was found to be two-folded higher in women than men (Blazer, Kessler, McGonagle, \& Swartz, 1994; Kessler \& Bromet, 2013; Murphy et al., 2000). Moreover, several studies demonstrated that the risk for depression remains higher among women than men after controlling for other factors (Eaton \& Kessler, 1981; Blazer et al., 1994; Weissman et al., 1996). It has been suggested that for men, the desire for muscularity is a component of their body image and that a higher drive for muscularity correlates with a lower level of well-being (Swami et al., 2018). In Israel some of the studies indicated on similar relationship while other did not show association between gender and depression (Geulayov et al. 2007; Kafman, Alon \& Hermoni, 2003; Weissman et al., 1996).

The associations between age and depression are not consistent (Remick, 2002), and contradictory reports were received in the literaturereview concerning this relationship. Some of them indicated on positive relationship, i.e. the higher the age groups the higher the prevalence rates of depression, while other demonstrated a negative relationship between age and depression (Kessler \& Bromet, 2013). In addition, other studies have found a decrease in the prevalence of major depression disorders with age, whilst a minor depression disorder and symptomatic disorders increased with age. This finding may explain the inconsistent relationship between age and depression (Iancu et al., 2003). The evidence in Israel regarding the association of age and depression is mixed: in one study among individuals aged 21-65 it has been found that the risk for depression is increased at age 40 and above, whereas in two other studies no direct and consistent association has been found between the prevalence of depression and age (Iancu et al., 2003; Herrman et al., 2002; Rivlis, 2006).

Based on comprehensive review, it was shown that most of the studies demonstrate negative relationship between religiosity level and depression. i.e., higher religiosity levels are related to lower rate of depression. However, these findings are still inconclusive and some of the studies indicate on positive relationship between both, religiosity level and depression (Bonelli, Dew, Koenig, Rosmarin \& Vasegh, 2012). One Israeli study found a relationship between participation in religious activities and lower rates of depression while the second one did not detect association between religiosity and depression (Levin, 2012; Lupo \& Strous, 2011). Blazer and colleagues (1994) found that individuals living without a partner (being single, separated, widower or divorced) and with lower education level are in higher risk for developing major depression. These trends were replicated in additional studies in different countries (Rivlis, 2006; Weissman et al., 1996; Eaton \& Kessler, 1981). However, in Israel these findings were mixed and inconclusive (Geulayov et al. 2007).

There are diverse strategies for treating depressive disorders which are considered to be effective, including psychotherapy and medical intervention (Lowe et al., 2004; Manning \& Jackson, 2015). Antidepressant medications can be effective in treating depressive disorder among $80 \%$ of the depressed individuals. 
In addition, psychotherapeutic interventions have an equivalent effectiveness to antidepressant medications when used for mild depressive disorders (Banazak, 2000; Remick, 2002; Manning \& Jackson, 2015). However, it was found that many individuals with severe depressive disorders are not identified (Simon et al., 2004) and are not treated as required (Shvartzman et al., 2005). Previous studies showed that primary physicians diagnose around $36 \%-64 \%$ of patients who are suffering from depression (Kafman et al., 2003). It can be partially explained by the fact that depressive disorders include physical symptoms that are mistakenly interpreted as a physical condition, instead of a mental one (Kafman et al., 2003; Mitchell, Vaze \& Rao, 2009). In addition, socio-cultural factors may also play a role in the detection and treatment of depression. The Israeli society is relatively diverse in terms of ethnic groups, customs, beliefs and mother tongue. This situation may pose challenges in supplying diagnosis and treatment services for depression in Israel (Geulayov et al., 2007).

Previous studies that examined the relationship between residence place and depression yielded inconclusive results. Some of them showed that there is no association between rural and urban areas and prevalence of depression while other indicated on higher rates of the depression in rural areas or vice versa (Probst et al., 2006). Although the association between socio-demographic and depression were examined in previous studies (Kaplan et al., 2010; Iancu et al., 2003), these findings remained inconclusive in Israel and abroad. Moreover, these associations and their trend may change overtime. Therefore, there is a room for additional studies aiming to examine the nature of these relationships. The current study have several purposes: (1) To examine the depression rates by socio-demographic characteristics among the Jewish and the Arab population groups; (2) To examine the independent role of population group affiliation in predicting depression among the Israeli adult population, with emphasis on cultural aspects; (3) To identify socio-demographic predictors for depression among the Jewish and the Arab population groups.

\section{Methodology}

This study was based on a cross-sectional survey, the third Israeli national health interview survey which was carried out by the Israel Center for Disease Control in 2013-2015.

\section{Study participants}

Participants in this survey were Jewish and Arab Israeli residents aged 21 and older. A random sample of landline telephone numbers households was drawn from a comprehensive list of the national telephone company. Fax numbers, disconnected numbers, commercial and business numbers and households without a resident 21 years and older were ineligible and thus excluded from the sample. Following this exclusion, 6,636 households (4,699 Jewish households and 1,937 Arab households) were found to meet the required criteria. In each household, only one person was interviewed. Overall, 3,765 interviewees (2,610 from Jewish 
households and 1,155 interviewees from Arab households) agreed to participate in the survey and completed the interview as required. Thus, the responsiveness rate was $55.5 \%$ for Jews and $59.6 \%$ for Arabs.

\section{The questionnaire}

Self-reported data were collected by telephone interviews. The interview was conducted in Hebrew among the Jewish population and in Arabic among the Arab population. The interviews were conducted by trained interviewers, native speakers of Hebrew or Arabic. The current research is based on the information that was collected as part of this survey.

The questionnaire in the third survey included issues related to socio-demographic factors, health status, self-report on chronic conditions or diseases, use of health services and health-related behaviors. In addition, this questionnaire included a shortened five-item version of the Mental Health Index (MHI-5) (Shor \& Delbar, 2014; Rumpf, Meyer, Hapke, John, 2001). This tool was derived from a wider instrument, the SF-36 [The Short Form (36) Health Survey], which is composed of eight health-related subscales, including mental health (Shor \& Delbar, 2014). The MHI-5 includes all five items appearing in the "mental health" subscale. The interviewees are asked to indicate at what frequency during the last four weeks they experienced various emotional states (like despair and depression) based on the following categories: "all of the time", "most of the time", "a good bit of the time", "some of the time", "a little of the time", or "none of the time". In each question it is possible to accumulate points in the range of 5-30. Afterwards the mark is translated to a scale which ranges between the values 0-100 and the calculation is based on an average mark for all the questionnaire items (Geulayov et al., 2010).

The MHI-5 was found to be an appropriate instrument for identifying depression in diverse populations and serves for detecting depression related symptoms in different studies, including the two waves of the nurses' study in Harvard, The Nurses' Health Study 1 and 2 (Friedman, Heisel \& Delavan, 2005; Huang et al., 2015; Pan et al., 2010). In studies in which this questionnaire was validated against structured interviews, it was found that the optimal cut-off score for detecting depression sets up at 60 in the general adult population. Individuals that accumulated less than 60 points are suspected to have a clinical depression (major depressive disorder) (Geulayov et al., 2010; Rumpf et al., 2001).

\section{Study Variables}

\section{Dependent Variable}

Depression Status: Existence of depression was determined according to the results of the MHI-5 questionnaire. Interviewees that accumulated less than 60 points were defined as "depressed"; otherwise they were defined as "non-depressed". 


\section{Main Independent Variables}

Population Group: Jews and non-Arab Christians were included in the Jewish population group. Muslims, Arab Christians, Druze and Bedouins were included in the Arab population group; Gender: the gender of each interviewee was recorded by the interviewers; AgeGroup: the interviewees were asked to report their age at the time of the survey and year of birth. Based on this information they were classified into two age groups: 21-64, 65+; Religiosity: The interviewees defined their religiosity according to the following categories: secular, traditional, religious or very religious. Accordingly, the interviewees were classified into two groups: "secular" for the first category or "religious" for any of the next three categories; Marital Status: The interviewees reported about their marital status based on the following categories: married or living with a spouse, separated, divorced, widowed or single. Accordingly, the interviewees were defined as "living with a spouse" for the first category or "living without a spouse" for any of the next categories; Education Level: The overall self-reported years of education were combined into two categories: less than 12 years of education and 12 or more years of education; A Residential Area: The interviewee were classified into four residential areas based on the six districts in which they live: "North Area" for North district or Haifa district, "Central Area" for Central district or Tel Aviv district, "Jerusalem Area" area or "Southern Area";

\section{Confounders - Basic Health Characteristics}

General Health Status: The interviewees reported whether their general health status is usually "very good", "good", "not so good" or "not good at all"; Chronic Conditions: The interviewees were asked about medical diagnosis of at least one of the following: chronic conditions: asthma, hypertension, high cholesterol, high triglycerides, heart disease, stroke, any cancer disease and diabetes; Body Mass Index (BMI): BMI was calculated by dividing the reported weight (in kilograms) by the square of reported height (in meters).

\section{Statistical analysis}

Due to possible effect of cultural differences between the Jewish and the Arab populations, data were analyzed separately for each population group. The rates of depression as defined above were calculated for the entire sample and by population group and by the other socio-demographic characteristics mentioned above. Bivariate analyses were done by $\chi 2$ test for examining associations between socio-demographic variables and depression. In order to evaluate the independent effect of population group on the risk for depression, multivariable logistic regression was employed in the entire study population (Jews and Arabs) while controlling for the other socio-demographic and health characteristics. The significant variables that were found in the bivariate analyses among Jews and Arabs were included in two separate multivariable models of logistic regression (one model per population group). These models were run in order to identify predictors for 
depression among Jews and among Arabs. The basic health characteristics that may be confounders were controlled for both models. SPSS software (version 24) was used and statistical significance was set at $\mathrm{p}<0.05$.

\section{Results}

The current study included 3,765 interviewees: 2,610 Jewish respondents (50.3\% men and $49.7 \%$ women) and 1,155 Arab respondents $(47.4 \%$ men and $52.6 \%$ women). Table 1 presents the socio-demographic characteristics of the Jewish and Arab population groups. Most of the interviewees were aged 21-64 among the two population groups. However, their proportion among Jews was significantly lower than in the Arab sector $(71.3 \%$ and $88.2 \%$, respectively, $\mathrm{p}<0.01)$. While almost half of the Jewish interviewees defined themselves as secular people, less than $15 \%$ of the Arabs were classified as secular people $(49.0 \%$ and $14.2 \%$, respectively, $\mathrm{p}<0.01$ ). Around $80 \%$ of the interviewees reported that they live with a partner in both population, Jews (82.6\%) and Arabs (80.2\%). The proportion of interviewees who completed at least 12 years of schooling was significantly higher among Jews than in Arabs (90.2\% and 68.4\%, respectively, $\mathrm{p}<0.01)$. The most reported residential area was the Central region among Jews $(49.2 \%)$ and the Northern region among Arabs (58.6\%).

Table 1. Socio-demographic characteristics of the interviewees by population group

\begin{tabular}{|c|c|c|c|c|c|}
\hline \multirow[t]{2}{*}{$n$} & & \multicolumn{2}{|c|}{ Jews $(n=2,610)$} & \multicolumn{2}{|c|}{$\operatorname{Arabs}(n=1,155)$} \\
\hline & & $\%$ & $n$ & $\%$ & \\
\hline \multirow{2}{*}{ Gender } & Men & 1,314 & 50.3 & 548 & 47.4 \\
\hline & Women & 1,296 & 49.7 & 607 & 52.6 \\
\hline \multirow{2}{*}{$\begin{array}{l}\text { Age } \\
\text { group }\end{array}$} & $21-64$ & 1,862 & 71.3 & 1,019 & 88.2 \\
\hline & $\geq 65$ & 748 & 28.7 & 136 & 11.8 \\
\hline \multirow{2}{*}{ Religiosity } & Non-religious & 1,267 & 49.0 & 159 & 14.2 \\
\hline & Religious & 1,320 & 51.0 & 962 & 85.8 \\
\hline \multirow{2}{*}{$\begin{array}{l}\text { Marital } \\
\text { status }\end{array}$} & $\begin{array}{l}\text { Without a } \\
\text { spouse }\end{array}$ & 453 & 17.4 & 229 & 19.8 \\
\hline & With a spouse & 2,153 & 82.6 & 926 & 80.2 \\
\hline \multirow{2}{*}{$\begin{array}{l}\text { Education } \\
\text { (years) }\end{array}$} & $<12$ & 253 & 9.8 & 362 & 31.4 \\
\hline & $\geq 12$ & 2,322 & 90.2 & 791 & 68.4 \\
\hline
\end{tabular}




\begin{tabular}{|l|l|l|l|l|l|}
\hline \multirow{4}{*}{$\begin{array}{l}\text { Residential } \\
\text { area }\end{array}$} & North & 575 & 22.0 & 677 & 58.6 \\
\cline { 2 - 6 } & Central & 1,284 & 49.2 & 137 & 11.9 \\
\cline { 2 - 6 } & Jerusalem & 397 & 15.2 & 275 & 23.8 \\
\cline { 2 - 6 } & South & 454 & 13.6 & 66 & 5.7 \\
\hline
\end{tabular}

The prevalence of depression in the entire sample was $13.8 \%$. The rate of depression was significantly higher among the Arab group than the Jewish group $(23.9 \%$ and $9.3 \%$, respectively, $\mathrm{p}<0.01)$. This trend remained significant also after controlling for the following socio-demographic and basic health characteristics: gender, age group, religiosity, marital status, education level, residential area general health status, chronic conditions and BMI $(\mathrm{OR}=2.77, \mathrm{p}<0.01)$.

Table 2 presents the prevalence rates of depression among Jewish and Arab population groups by socio-demographic characteristics. In each population group, of Jews and Arabs, higher rates of depression were found among women, among religious interviewees and among those who have low education level. In both population groups there was significant association between residential area and depression. The highest rate of the depression was detected in the south area among Jews and in the north among Arabs. In addition, higher rates of depression were found among those who live alone in the Jewish group and among those who are aged 21-64 in the Arab population.

Table 2. Prevalence of depression among Jewish and Arab population groups by socio-demographic factors

\begin{tabular}{|c|c|c|c|c|c|}
\hline & & \multicolumn{2}{|c|}{ Jews $(n=2,610)$} & \multicolumn{2}{|c|}{ Arabs $(n=1,555)$} \\
\hline & & $\mathrm{n}$ & $\%$ & $\mathrm{n}$ & $\%$ \\
\hline \multirow{3}{*}{ Gender } & Men & 1,314 & 8.1 & 548 & 17.3 \\
\hline & Women & 1,296 & 10.6 & 607 & 29.8 \\
\hline & $p$ & & $<0.05$ & & $<0.01$ \\
\hline \multirow{3}{*}{$\begin{array}{l}\text { Age } \\
\text { group }\end{array}$} & $21-64$ & 1,862 & 9.1 & 1,019 & 25.0 \\
\hline & $\geq 65$ & 748 & 9.9 & 136 & 15.4 \\
\hline & $\mathrm{p}$ & & n.s. & & $<0.05$ \\
\hline \multirow{3}{*}{ Religiosity } & Non-religious & 1,267 & 7.8 & 159 & 17.6 \\
\hline & Religious & 1,320 & 10.6 & 962 & 25.2 \\
\hline & $p$ & & $<0.05$ & & $<0.05$ \\
\hline \multirow{3}{*}{$\begin{array}{l}\text { Marital } \\
\text { status }\end{array}$} & $\begin{array}{l}\text { Without a } \\
\text { spouse }\end{array}$ & 453 & 15.5 & 229 & 28.4 \\
\hline & With a spouse & 2,153 & 8.1 & 926 & 22.8 \\
\hline & $p$ & & $<0.01$ & & n.s. \\
\hline
\end{tabular}


SOCIAL RESEARCH REPORTS - VOLUME 11, ISSUE 1 - MARCH 2019

\begin{tabular}{|c|c|c|c|c|c|}
\hline \multirow{4}{*}{$\begin{array}{c}\text { Education } \\
\text { (years) }\end{array}$} & $<12$ & 253 & 20.9 & 362 & 27.6 \\
\cline { 2 - 6 } & $\geq 12$ & 2,322 & 8.0 & 791 & 22.3 \\
\cline { 2 - 6 } & $\mathrm{p}$ & & $<0.01$ & & $<0.05$ \\
\hline \multirow{4}{*}{$\begin{array}{c}\text { Residential } \\
\text { area }\end{array}$} & North & 575 & 7.8 & 677 & 27.5 \\
\cline { 2 - 6 } & Central & 1,284 & 9.7 & 137 & 16.1 \\
\cline { 2 - 6 } & Jerusalem & 397 & 6.8 & 275 & 18.2 \\
\cline { 2 - 6 } & South & 454 & 13.3 & 66 & 27.2 \\
\cline { 2 - 6 } & $\mathrm{p}$ & & $<0.01$ & & $<0.01$ \\
\hline
\end{tabular}

Table 3 presents logistic regression models that identified predicting socio-demographic factors for depression. As mentioned above, models were run for the Jewish and Arab population groups separately while they are controlled for basic health characteristics. In the Jewish population, women, interviewees who live alone and those who have low education level were more likely to be depressed. The following variables were not associated with depression in this population group: religiosity and residential area.In the Arab population, women, interviewees aged 21-64 and those who live in the north or in the south area were more likely to be depressed. The following variables were not related to depression in this population group: religiosity and education level.

Table 3. Predicting factors of depression among Jewish and Arab population groups by multiple logistic regression models*

\begin{tabular}{|c|c|c|c|c|c|}
\hline & & \multicolumn{2}{|c|}{ Jews $(n=2,610)$} & \multicolumn{2}{|c|}{ Arabs $(n=1,155)$} \\
\hline & & OR & $95 \% \mathrm{Cl}$ & OR & $95 \% \mathrm{Cl}$ \\
\hline \multirow{3}{*}{ Gender } & Women & 1.6 & $1.1-2.2$ & 2.0 & $1.4-2.7$ \\
\hline & Men & Ref & & Ref & \\
\hline & $p$ & $<0.01$ & & $<0.01$ & \\
\hline \multirow{3}{*}{$\begin{array}{l}\text { Age } \\
\text { group }\end{array}$} & $21-64$ & - & - & 3.7 & $1.9-7.5$ \\
\hline & $\geq 65$ & - & - & Ref & \\
\hline & $p$ & & - & $<0.01$ & \\
\hline \multirow{3}{*}{ Religiosity } & Non-religious & - & - & - & - \\
\hline & Religious & - & - & - & - \\
\hline & $\mathrm{p}$ & & - & & - \\
\hline \multirow{3}{*}{$\begin{array}{l}\text { Marital } \\
\text { status }\end{array}$} & $\begin{array}{l}\text { Without a } \\
\text { spouse }\end{array}$ & 1.8 & $1.2-2.6$ & - & - \\
\hline & With a spouse & Ref & & - & - \\
\hline & $p$ & $<0.01$ & & & - \\
\hline
\end{tabular}




\begin{tabular}{|c|c|c|c|c|c|}
\hline \multirow{3}{*}{$\begin{array}{l}\text { Education } \\
\text { (years) }\end{array}$} & $<12$ & 2.0 & $1.3-3.0$ & - & - \\
\hline & $\geq 12$ & Ref & & - & - \\
\hline & $\mathrm{p}$ & $<0.01$ & & & - \\
\hline \multirow{7}{*}{$\begin{array}{l}\text { Residential } \\
\text { area }\end{array}$} & North & - & - & 1.9 & $1.1-3.1$ \\
\hline & $\mathrm{p}$ & & & $<0.05$ & \\
\hline & South & - & - & 2.0 & $1.2-3.2$ \\
\hline & $\mathrm{p}$ & 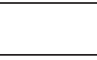 & & $<0.05$ & \\
\hline & Jerusalem & - & - & 1.6 & $0.9-2.7$ \\
\hline & $\mathrm{p}$ & & & n.s. & \\
\hline & Central & - & - & Ref & \\
\hline
\end{tabular}

* Both models were controlled for the following basic health characteristics: general health status, chronic conditions and BMI (data is not shown).

\section{Discussion}

In this study, the rates of depression were estimated among the adult population in Israel, with emphasis on Jews and Arabs. In addition, the socio-demographic factors that may enhance the probability of depression were examined among Jews and among Arabs.

It was found that the rate of depression was $13.8 \%$ by scale-based tool (MHI$5)$ in the entire research population. In previous studies in Israel, which also used scale-based tools, rates of depression were higher than in the current research: 17.8\% and 21.5\% (Kaplan et al., 2010; Iancu et al., 2003). These findings may imply on a decline in the rate of depression in Israel. This decline may be attributed to efforts made for increasing a public awareness about depression and its implications through various channels, such as the Ministry of Health Website. These tools enable access to relevant information in several languages, including Hebrew and Arabic (Ministry of Health, n.d.). However, there is still high rate of adult individuals in the general population in Israel who cope with depression or related symptoms to depression. This situation indicates on the importance of reducing the extent of depression among the Israeli adult population.

A significant gap was found in the rates of depression between Arabs and Jews. The rate of depression among the Arab population was 2.6 times higher than among the Jewish population (23.9\% and $9.3 \%$, respectively). This difference remained significant also after controlling for the other studied socio-demographic factors and for basic health characteristics. A similar gap was observed in former studies and was explained by the lower education level and poorer health status among the Arab population compared to the Jewish population (Kaplan et al., 2010). However, in the current study this difference remained significant also after controlling for 
socio-demographic and basic health characteristics (including education level and general health status). The Arab population constitutes a minority group in Israel (about $20 \%$ of the total population in Israel) (Israel Center Bureau of Statistics, 2014). This minority group has unique cultural characteristics that influence its attitudes and patterns of coping with healthissues, including mental disorders. Religious beliefs, perception of family as a supreme value, and the stigma which is associated with related problems to mental health consist for barriers for diagnosis of mental disorders and coping with them among the Arab population in Israel. Expression of emotional distress is less common in the Arab society than in Jewish society (Baron-Epel et al., 2005); therefore, Arabs who experience mental disorder may deny their situation and avoiding from turning to professionals in the field. Alternatively, they would search for therapeutic options only for the physical symptoms of the misdiagnosed depression.Moreover, existing health services may not be suitable for the cultural aspects and requirements of the Arab population. For example, Arabs man may avoid from using professional help if it is provided by a female therapist instead of a male therapist. Similarly, Arab patients may find it difficult to turn for therapy that is provided by a non-Arab therapist who is not familiar with their socio-cultural values. In addition, traditional medicine may take more significant place in the Arab culture than the Jewish culture (Al-Krenawi, 2005). As a result, Arabs may prefer to turn to healers who provide traditional medical interventions. These interventions might not be proven as an evidence-based efficient treatment for depression.

It was found that the likelihood for depression among women was higher than among men in both population groups, Jews and Arabs. These findings correspond with those of former studies around the world and in Israel (Kaplan et al., 2010; Kessler \& Bromet, 2013; Piccinelli \& Wilkinson, 2000). Compared with men, women have a higher likelihood of suffering from depression, due to biological and psychological factors. Studies have shown an association between hormonal changes and depression. In the course of their lives, women would likely cope with more hormonal changes, especially during the period of fertility: before and during menstrual cycle, during pregnancy etc. A variety of psychological factors may explain the increased likelihood of depression among women, such as socialization processes, interpersonal factors and characteristics which are associated with the structure of the personality (Albert, 2015; Noble, 2005). In the recent decades many women cope with a demanding lifestyle that requires them to combine between the employment framework and the burden of caring for children and maintaining the household. This lifestyle can lead to stress and a sense of distress that increases the risk of depression. In this situation, the absence of a relationship with a spouse or the active support of a spouse may also be associated with the occurrence of depression. In addition, some women have a tendency to waive on their personal needs and suppressing angers in order to fulfill their obligations with nurturing and maintaining intimate relationships. These patterns may increase personal distress and cause depression. The current research has showed that the probability of depression was higher at the younger age group (aged 21-64) compared with the age group of older adults (aged 65+) among Arab group only. Among Jews, this variable was not associated with depression at the bivariate analysis. In several studies, an association between age 
and depression was observed (Iancu et al., 2003; Kessler \& Bromet, 2013). In later stages of life, most of the older adult people cope with physical limitations, bereavement, and other stressful events alongside with changes to the immune system, cognitive function, and other biological systems that may increase their risk for developing depression. However, there are social and psychological factors that protect the old population from the development of depression or depressive symptoms. Improved emotional regulation, which is related to aging, has a strong protective effect against the development of depression in older adults. Older adults tend to be less sensitive to stressors in comparison to adults at younger ages. In addition, older adults, compared with younger adults, focus more on positive life events with emotional value. Some also have a good self-perception alongside with self-efficacy and a sense of control with regard to their lives. Studies have shown that adults with limitations in functioning may recover from depressive symptoms if they find other alternatives to the same limitations (Fiske, Wetherell $\&$ Gatz, 2009). It is possible that these protective factor provide a more significant advantage among the Arab population due to cultural and accessibility barriers to mental health services, including medical interventions for depression (Al-Krenawi, 2005). Therefore, the difference in the likelihood of depression based on the age group was not found to be significant among the Jewish population.

In the bivariate analyses, there was a correlation between religiosity and depression. In both, Jewish and Arab groups, the rates of depression were higher in religious interviewees than secular people. However, in the multivariable analyses in both population the association was not significant. The influence of religiosity on health related issues may act in two opposite directions. On the one hand, various religions emphasize the high value of life and the importance of health maintaining. Therefore, each person is obligated to perform the necessary actions to keep healthy lifestyle. Moreover, in special circumstances these actions may lead to violation of religious commandments, such as avoidance from fasting in particular date due to health restrictions (Bowen, Signal, Eng, Crystal \& Burke, 2003; Lawrence \& Rozmus, 2001). On the other hand, the principles of religion may consist for barrier for turning to medical experts and using health services. For example, some religious people may avoid specific medical services due to physical modesty issues or because they may percept the disease as punishment by force majeure (Azaiza \& Cohen, 2008).

This research showed that the likelihood of depression was higher among individuals who live alone than those who live with a spouse among Jews only. Among Arabs, this variable was not associated with depression at the bivariate analysis. The association between marital status and depression was demonstrated in former researches as well (Blazer et al., 1994; Kaplan et al., 2010). People living in solitude are at increased risk of social isolation. Individuals who suffer from social isolation receive less social and instrumental support than those who do not live alone. This isolation may increase the likelihood of depression among such people (Stahl, Beach, Musa \& Schulz, 2017). The principle of collectivism in Israel is much more significant among the Arab population compared to the Jewish population. The guiding values of members of a group who act according to this principle are social solidarity, mutual responsibility and a shared sense of belonging at the level of the nuclear family, the extended family, the neighborhood 
and the entire community (Malach-Pines \& Zaidman, 2003). Research evidences suggest that depression levels are lower among individuals who live alone and receive support from neighborhood members, compared with those who live alone without the support of neighborhood members (Stahl et al., 2017). Accordingly, it is possible that individuals who live alone in the Arab population receive sufficient support from members of the neighborhood, which constitutes a partial or full substitute for the support of life partners. This may explains why no relationship was found between marital status and depression among Arabs.

The current study found a higher likelihood of depression among individuals with low education level (less than 12 schooling years) than those with high education level (12 years or more years) among Jews only at the multivariable analyses. The correlation between education level and depression is supported by findings of former studies (Blazer et al., 1994; Kaplan et al., 2010). There are several explanations to the fact that higher education is related to good mental health. Higher level of education increases the individuals' chances of integrating into fields of activity that provide them higher social status that improve their well-being, including establishment of self-worth. Moreover, higher levels of education may reduce the risk of unemployment and enable access to senior positions with high salary levels. In addition, the acquisition of education contributes to the development and establishment of capabilities, knowledge, skills, attitudes and values. These may provide the individual "a kit" of tools and capabilities to cope with problems in the workplace and in daily life. Another aspect, individuals with higher education, compared with those with less education, have more opportunities to create and maintain social networks that can be supportive and contributing to better mental health (Bracke, Pattyn \& von dem Knesebeck, 2013). Among the Arab population in the research, this finding was not significant. It is possible that the mutual responsibility and assistance that are customary among the Arab society at the level of the neighborhood and the community (Malach-Pines \& Zaidman, 2003) reduces the likelihood of depression in risk groups, such as those with low levels of education.

Among Arabs, the likelihood of depression was higher among individuals who live in the northern and southern areas than those live in the central area. This finding was not observed in the Jewish group at multivariable analyses. In residential areas where the percentage of Arabs is high with relation to the national population distribution (in the north and south), there may be a deficiency of medical services and staff. In contrast, the Jewish population is concentrated mainly in the central and Jerusalem areas, where these deficiencies may be less prominent. The rate of dissatisfaction with the availability of primary and secondary care settings was higher among Arabs compared to Jews (Chernichovsky, Bisharat, Bowers, Brill \& Sharony, 2017). It is possible that due to lower accessibility of health services in the north and south, in areas of concentration of the Arab population, the opportunities of detecting undiagnosed depression among Arabs are more limited compared to areas of higher accessibility of these services (in both, central and Jerusalem areas in which there are higher concentration of the Jewish population). 


\section{Study Implications}

The associated factors with depression in each one of the two population groups were partially different. These findings reinforces the need in tailoring a unique intervention plan for each population group (Jews or Arabs), which focuses on the sub-groups at higher risk for depression. These plans should put an emphasis on the native language, traditions, customs, social codes and cultural barriers for health services utilization, in order to make a change in consciousness among these populations. These plans may result in increased awareness for depression and its harmful implications. Moreover, an increased awareness for depressive disorders may help in enhancing the compliance with recommended treatment for depression and in reducing the extent of the disorder in Israel. These intervention will require consultation with experts (clerics, community center managers etc.) in each population group. These experts may assist in building the intervention plans and simultaneously serving as community key figures that influence their own public opinions.

\section{Strength and Limitations}

This study has one main strength point. The study population was derived from the third national health survey conducted in Israel, based on a random sample of household in Israel, with a low probability of selection bias. However, the current study has three main limitations. First, the study type is cross-sectional and therefore it is not possible to determine the directionality of the relationship between some of the independent socio-demographic factors and the dependent variable - depression. Second, due to limitations of sample size, it was not possible to identify the associated factors with depression in different ethnic sub-groups within each of the two main studied population groups, Jews (e.g., Ashkenazi and Oriental populations) and Arabs (e.g., among Christians, Bedouins, Druze and others). Third, the identification of depression cases in the current study was done by a scale-based questionnaire that serves as screening tool for depression. This tool does not provide accurate diagnosis of clinical depression and may result in false positive cases of depression. Moreover, in order to obtain valid and robust results, future studies should take into consideration to use a validated and culturally adapted scale (Tudorel et al., 2018; Vintila et al., 2018) to measure depression.

\section{Conclusion}

The current study found that around $14 \%$ of the adult population in Israel suffers from depression, with a significantly higher rate among Arabs than among Jews (around 24\% and 9\%, respectively). The overall rate was lower than the rates which were found in previous studies, which used scale-based questionnaires: $17.8 \%$ and 21.5\% (Kaplan et al., 2010; Iancu et al., 2003). These findings may indicate on a decline in the rate of depression in Israel due to increased awareness to depression and treatment options among the Israeli adult population. 
The gap in depression rates between Jews and Arabs may be explained by cultural differences that affect attitudes and patterns of coping with health-related conditions, including depression (Al-Krenawi, 2005; Baron-Epel et al., 2005; Cohen \& Azaiza, 2007). In this study, several socio-demographic characteristics were associated with depression. As found in previous research findings, the likelihood of depression was greater for women than men (Kaplan et al., 2010; Kessler \& Bromet, 2013; Piccinelli \& Wilkinson, 2000) among both, Jews and Arabs. Probably, the explanation for this difference is related to biological factors and psychological factors which are specific to women (Albert, 2015; Noble, 2005).

The likelihood for depression was higher in the younger age group (aged 21-64) compared with elders (aged 65+) among Arabs. In several studies an association between age and depression was observed (Iancu et al., 2003; Kessler \& Bromet, 2013). There are probably social and psychological factors that protect this population from the development of depression, such as an improvement in emotional regulation. These factors may provide a more significant advantage among the Arab population compared to Jewish population that cope with less barriers for using related medical services for depression (Al-Krenawi, 2005).

The likelihood for depression was higher among individuals who live alone than among those who live with a spouse among Jews, but not among Arabs. The association between marital status and depression was also observed in former studies (Blazer et al., 1994; Kaplan et al., 2010). People who live alone are at an increased risk for social isolation, which in turn increases the risk for depression (Stahl et al., 2017). Perhaps individuals who live alone in the Arab population receive considerable support from neighborhood members (as part of the common principle of collectivism in this society), which is a substitute for the support of life partners. Thus, these individuals are not at an increased risk for depression (Malach-Pines \& Zaidman, 2003).

This study found that the probability of depression tend to be higher among individuals with low education levels compared to those with higher education levels among Jews, but not among Arabs. The association between the education level and depression is supported by previous scientific evidences (Blazer et al., 1994; Kaplan et al., 2010). Higher education may provide the individual high socioeconomic status and "a kit" of tools for coping with problems in work and in daily life, including emotional distress (Bracke et al., 2013). Among the Jews only, interviewees that live alone or have low education level had increased likelihood for depression. It is possible that the collectivism which is expressed by mutual support in the Arab society (Malach-Pines \& Zaidman, 2003) reduces the likelihood of depression in certain Arab risk groups, such as those who live alone of have low education level.

In the Arab population, a higher likelihood of depression was found among individuals who live in the northern and southern areas of Israel than among those who live in the central area. This finding was not observed among Jews. It is possible that due to lower accessibility of health services in the north and south areas where the Arab population is more prominent, the opportunities of detecting undiagnosed depression among this population are more limited.

The current study reinforces the need in tailoring a unique intervention plan for each population group (Jews or Arabs), which focuses on the sub-groups at higher 
risk for depression. These programs should put an emphasis on cultural aspects and barriers for health services utilization, in order to plan an efficient intervention which result in enhancing the compliance with recommended treatment for depression and in reducing the extent of the disorder in Israel.

\section{References}

Albert, P.R. (2015). Why is depression more prevalent in women? Journal of Psychiatry and Nueroscience, 40, 219-221.

Al-Krenawi, A. (2005). Socio-political aspects of mental health practice with Arabs in the Israeli context. The Israel Journal of Psychiatry and Related Sciences, 42, 126-136.

American Psychiatric Association. (2013). Diagnostic and statistical manual of mental disorders (5 $5^{\text {th }}$ ed.). Arlington, VA: American Psychiatric Publishing.

Azaiza, F. \& Cohen, M. (2008). Between traditional and modern perceptions of breast and cervical cancer screenings: a qualitative study of Arab women in Israel. Psycho-oncology, 17, 34-41.

Banazak, DA. (2000). Minor depression in primary care. The Journal of the American Osteopathic Association, 100, 783-787.

Baron-Epel, O., Kaplan, G., Haviv-Messika, A., Tarabeia, J., Green, MS. \& Kaluski, DN. (2005). Self-reported health as a cultural health determinant in Arab and Jewish Israelis MABAT--National Health and Nutrition Survey 1999-2001. Social Science and Medicine, 61, 1256-1266.

Blazer, DG., Kessler, RC., McGonagle, KA. \& Swartz MS. (1994). The prevalence and distribution of major depression in a national community sample: the National Comorbidity Survey. The American Journal of Psychiatry, 151, 979-986.

Bonelli, R., Dew, RE., Koenig, HG., Rosmarin, DH. \& Vasegh, S. (2012). Religious and spiritual factors in depression: review and integration of the research. Depression Research and Treatment, doi: 10.1155/2012/962860.

Bowen, DJ., Singal, R., Eng, E., Crystal, S. \& Burke, W. (2003). Jewish identity and intentions to obtain breast cancer screening. Cultural Diversity \& Ethnic Minority Psychology, 9, 79-87.

Bracke, P., Pattyn, E. \& von dem Knesebeck, O. (2013). Overeducation and depressive symptoms: diminishing mental health returns to education. Sociology of Health and Illness, 35, 1242-1259.

Chernichovsky, D., Bisharat, B., Bowers, L., Brill, A. \& Sharony, C. (2017). The health of the Arab Israeli population. Retrieved from: http://taubcenter.org.il/wp-content/ files_mf/healthofthearabisraelipopulation.pdf

Cohen, M. \& Azaiza, F. (2007). Health-promoting behaviors and health locus of control from a multicultural perspective. Ethnicity and Disease, 17, 636-642.

Dunlop, D.D., Song, J., Lyons, J.S., Manheim, L.M. \& Chang, R.W. (2003). Racial/ethnic differences in rates of depression among preretirement adults. American Journal of Public Health, 93, 1945-1952.

Eaton, W.W. \& Kessler, L.G. (1981). Rates of symptoms of depression in a national sample. American Journal of Epidemiology, 114, 528-538.

Elizur, E.S., Tyano, S., Munitz, H., \& Neumann, M. (2010). Selected chapter in psychiatry. Tel Aviv, IL: Probook. 
Fiske, A., Wetherell, J.L. \& Gatz, M. (2009). Depression in older adults. Annual Review of Clinical Psychology, 5, 363-389.

Friedman, B., Heisel, M. \& Delavan, R. (2005). Validity of the SF-36 five-item Mental Health Index for major depression in functionally impaired, community-dwelling elderly patients. Journal of the American Geriatrics Society, 53, 1978-1985.

Geulayov, G., Lipsitz, J., Sabar, R. \& Gross R. (2007). Depression in primary care in Israel. The Israel Medical Association journal, 9, 571-578.

Geulayov, G., Goral, A., Muhsen, K., Lipsitz, J. \& Gross, R. (2010).

ivity among adults with diabetes mellitus and depressive symptoms: results from two independent national health surveys. General Hospital Psychiatry, 32, 570-576.

Herrman, H., Patrick D.L., Diehr P., Martin M.L., Fleck M., Simon GE. \& Buesching D.P. (2002). Longitudinal investigation of depression outcomes in primary care in six countries: the LIDO study. Functional status, health service use and treatment of people with depressive symptoms. Psychological Medicine, 32, 889-902.

Hidaka, B.H. (2012). Depression as a disease of modernity: explanations for increasing prevalence. Journal of Affective Disorders, 140, 205-214.

Huang, T., Poole, E.M., Okereke O.I., Kubzansky, L.D., Eliassen, A.H., Sood A.K., . . . Tworoger, S.S. (2015). Depression and risk of epithelial ovarian cancer: Results from two large prospective cohort studies. Gynecologic Oncology, 139, 481-486.

Iancu, I. Horesh, N., Lepkifker, E. \& Drory, Y. (2003). An epidemiological study of depressive symptomatology among Israeli adults: prevalence of depressive symptoms and demographic risk factors. Israel Journal of Psychiatry Related Science, 40, 82-89.

Israel Center Bureau of Statistics (2014). Population, by population group, religion, sex and age. Retrieved from: http:/www.cbs.gov.il/reader/shnaton/ shnatonh_new.htm?CYear $=2015 \&$ Vol $=66 \&$ CSubject $=2$

Kafman, M., Alon, N. \& Hermoni, D. (2003). Screening for depression in primary care clinics in Israel - how wide is the gap? Harefuah, 142, 815-819.

Kaplan, G., Glasser, S., Murad, H., Atamna, A., Alpert, G., Goldbourt, U. \& Kalter-Leibovici, O. (2010). Depression among Arabs and Jews in Israel: a population-based study. Social Psychiatry and Psychiatric Epidemiology, 45, 931-939.

Kessler R.C. \& Bromet E.J. (2013). The epidemiology of depression across cultures. Annual Review of Public Health, 34, 119-138.

Kessler, R.C., Birnbaum, H.G., Shahly, V., Bromet, E., Hwang, I., McLaughlin, K.A., . . S Stein, D.J. (2010). Age differences in the prevalence and co-morbidity of DSM-IV major depressive episodes: results from the WHO World Mental Health Survey Initiative. Depression and Anxiety, 27, 351-364.

Lawrence, P. \& Rozmus, C. (2001). Culturally sensitive care of the Muslim patient. Journal of Transcultural Nursing, 12, 228-233. 
Levin, J. (2012). Religion and physical health among older Israeli Jews: findings from the SHARE-Israel study. The Israel Medical Association Journal, 14, 595-601.

Levinson, D., Zilber, N., Lerner, Y., Grinshpoon, A. \& Levav, I. (2007). Prevalence of Mood and Anxiety Disorders in the Community: Results from the Israel National Health Survey. The Israel Journal of Psychiatry and Related Sciences, 44, 94-103.

Lowe, B., Spitzer, RL., Grafe, K., Kroenke, K., Quenter, A., Zipfel, S., . . . Herzog W. (2004). Comparative validity of three screening questionnaires for DSM-IV depressive disorders and physicians' diagnoses. The Journal of Affective Disorders, 78, 131-140.

Lupo, MK. \& Strous, RD. (2011). Religiosity, anxiety and depression among Israeli medical students. The Israel Medical Association Journal, 13, 613-618.

Malach-Pines, A. \& Zaidman, N. (2003). Israeli Jews and Arabs: similarities and difference in the utilization of social support. Journal of Cross-Cultural Psychology, 34, 465-480.

Manning, J.S., \& Jackson, W.C. (2015) Treating depression in primary care: initial and follow-up treatment strategies. The Journal of Clinical Psychiatry, 72 , e5.

Ministry of Health (n.d.). Depression across life span. Retrieved from: https://www. health.gov.il/Subjects/mental_health/LifeSituations/Pages/depression.aspx

Mitchell, AJ., Vaze, A., \& Rao, S. (2009). Clinical diagnosis of depression in primary care: a meta-analysis. Lancet, 374, 609-619.

Murphy, J.M., Laird, N.M., Monson, R.R., Sobol, A.M. \& Leighton A.H. (2000). A 40-year perspective on the prevalence of depression: the Stirling County Study. Archives of General Psychiatry, 3, 209-315.

Noble, R.E. (2005). Depression in women. Metabolism, 54(Suppl 1), 49-52

Pan, A., Lucas, M., Sun, Q., van Dam, R.M., Franco, O.H., Manson, J.E., . . . Hu, F.B. (2010). Bidirectional association between depression and type 2 diabetes mellitus in women. Archives of Internal Medicine, 170, 1884-1891

Piccinelli, M. \& Wilkinson, G. (2000). Gender differences in depression. Critical review. British Journal of Psychiatry, 177, 486-492.

Probst, J.C., Laditka, S.B., Moore, C.G., Harun, N., Powell, M.P., Baxley, E.G. (2006). Rural-urban differences in depression prevalence: implications for family medicine. Family Medicine, 38, 653-660.

Remick, R.A. (2002).Diagnosis and management of depression in primary care: a clinical update and review. Canadian Medical Association Journal, 26, $1253-1260$.

Rivlis, R. (2006). Nation health survey 2003/2004: selected findings. Retrieved from: http://www.cbs.gov.il/publications/briut_survey/pdf/h_print.pdf

Rumpf, H.J., Meyer, C., Hapke, U.\& John, U. (2001). Screening for menal health: validity of the MHI-5 using DSM IV Axis I psychiatric disorders as gold standard. Psychiatry Research, 105, 243-253. 
Shor, V \& Delbar V. (2014). Characteristics of quality of life among spouses of women with breast cancer in comparison to spouses of healthy women. The Israel Journal of Oncology Nursing, 24, 12-24.

Shvartzman, P., Weiner, Z., Vardy, D., Friger, M., Sherf, M. \& Biderman, A.(2005). Health services utilization by depressive patients identified by the MINI questionnaire in a primary care setting. Scandinavian Journal of Primary Health Care, 23, 18-25.

Simon, G.E., Fleck, M., Lucas, R. \& Bushnell, D.M.; LIDO Group. (2004). Prevalence and predictors of depression treatment in an international primary care study. American Journal of Psychiatry, 161, 1626-1634.

Stahl, S.T., Beach, S.R., Musa D. \& Schulz, R. (2017). Living alone and depression: the modifying role of the perceived neighborhood environment. Aging and Mental Health, 21, 1065-1071.

Swami, V., Vintila, M., Tudorel, O., Goian, C., \& Barron, D. (2018). Factor Structure and Psychometric Properties of a Romanian Translation of the Drive for Muscularity Scale. Body Image, 25; 48-55;

Tudorel, O. I., Vintilă, M., Vlaicu, L., Balauta, D., Goian, C., Rusu, A. (2018). Romanian version of the Internet Addiction Test: Psychometric properties and cross-gender invariance. International Journal of Mental Health and Addiction. doi: 10.1007/ s11469-018-0014-6;

Vintila, M., Tudorel, O.I., Goian, C., Barbat, C. (2018). Determining the structure of Smartphone Addiction Scale: A bifactor model analysis. Current Psychology Journal. doi: 10.1007/s12144-018-0035-0;

Weissman, M.M., Bland, R.C., Canino, G.J., Faravelli, C., Greenwald, S., Hwu, HG., . . . Yeh, E.K.(1996). Cross-national epidemiology of major depression and bipolar disorder. The Journal of the American Medical Association, 276, 293-299.

World Health Organization. (2005). The world mental health survey initiative. Retrieved from http://www.hcp.med.harvard.edu/wmh/

World Health Organization. (2016). Depression. Retrieved from: http://www.who.int/ mediacentre/factsheets/fs369/en/ 